\title{
Antibiyotikli çimento ve spacer uygulamaları
}

\author{
Antibiotic loaded cement and spacer applications
}

\author{
Fatih Küçükdurmaz, İbrahim Tuncay
}

Bezmialem Vakıf Üniveristesi Tıp Fakültesi Ortopedi ve Travmatoloji Anabilim Dalı, İstanbul

Kronik periprostetik eklem enfeksiyonların altın standart olarak kabul edilen tedavisi iki aşamalı cerrahidir. ilk aşamada enfekte implantın çıkarılmasını takiben sistemik antibiyotik ve lokal olarak antibiyotik salınımı yapan geçici yerini kaplayıcılar (spacer) kullanılır. Spacer'lar antibiyotik salınımı sağlayarak enfeksiyon tedavisi yapmanın yanı sıra, ikinci aşamaya kadar yumuşak dokunun tansiyonunu sağlamada faydalıdır. Spacer uygulamalarının çok çeşitli şekilleri vardır. Bunlar; hazır spacer uygulamaları, antibiyotikle karıştırılan çimentodan cerrahi sırasında elle hazırlananlar, elle hazırlananlarda antibiyotik seçimi, eklemli veya eklemsiz olanlar gibi farklı uygulamalardır. Bu derlemede, spacer ve antibiyotikli çimento uygulamalarındaki farklılıklar literatür ışığında incelenmiştir.

Anahtar sözcükler: periprostetik eklem enfeksiyonu; spacer; antibiyotik
Two-stage surgery is considered as the gold standard treatment in chronic periprosthetic joint infections. Following the removal of the infected implant during the first phase, spacers are used which release local antibiotics in addition to systemic antibiotics. Spacers are useful in treatment of infection by releasing antibiotics as well as keeping the tension of the soft tissues until the second stage. There are many different applications of spacers. The prefabricated or the hand made ones, prepared during the surgery; cement mixed with antibiotics and selection of antibiotics; dynamic or static ones are different options. In this paper, various applications of spacers and antibiotic loaded cements are reviewed.

Key words: periprosthetic joint infections; spacer; antibiotics
K ronik periprostetik eklem enfeksiyonlarının iki aşamalı cerrahi tedavisinin unsurları; enfekte implantın çıkarılması, yeterli debridman, lokal antibiyotik tedavisi, sistemik antibiyotik tedavisi ve enfeksiyonun eradikasyonunu takiben reimplantasyondur. Lokal antibiyotik tedavisi için kullanılan ve çıkarılan implantın yerine yerleştirilen çimentodan yapılan ve antibiyotik salınımı sağlayan, geçici yerini kaplayıcılar (spacer) kullanılır. Bunların, sistemik olarak verilemeyecek dozda antibiyotiği lokal olarak salma ve ikinci aşamaya kadar yumuşak dokunun tansiyonunu sağlama gibi temel iki faydası vardır. ${ }^{[1]}$ Bazı durumlarda ise sadece antibiyotik tedavisi açısından faydası olan boncuklar veya biyo-emilebilir materyaller de kullanılmakla beraber, bunlar bu derlemenin kapsamı dışında bırakılmıştır.

Spacer'lar hazırlanma, tasarım ve antibiyotik içeriği özelliklerine göre değerlendirilebilir. Spacer'ların, hazır olanları ve ameliyat sırasında cerrahlar tarafından elle veya çeşitli aparatlar yardımı ile hazırlananları mevcuttur. Her birisinin kendisine göre bazı avantaj ve dezavantajları vardır. Hazır olan imalat spacer'ların en önemli avantajları şunlardır ${ }^{[2]}$ :

1) Mekanik mukavemetleri daha fazladır.

2) Antibiyotik salınımları standart ve yeterli ölçüdedir.

3) Dizaynları açısından daha fazla harekete izin verir.

4) Uygulanmaları cerrahi süreyi uzatmaz.

Ancak, bu tip hazır spacer'ların en önemli dezavantajları, antibiyotik içeriği açısından sınılı ve yüksek maliyetli olmalarıdır. Bunlar çoğunlukla gentamisin içerir ve son zamanlarda gentamisinle sinerjestik özellik gösteren vankomisin eklenmiş olanları da mevcuttur.

Diğer taraftan, ameliyat sırasında cerrah tarafından da spacer hazırlanabilir. Bunların içerisine,

- Illetişim adresi: Prof. Dr. İbrahim Tuncay, Bezmialem Vakıf Üniversitesi Tıp Fakültesi, Ortopedi ve Travmatoloji Anabilim Dalı, Adnan Menderes Bulvarı, Fatih, İstanbul Tel: 0212 - 4531700 / 2273 e-posta: ituncay@gmail.com

- Geliș tarihi: 1 Mart 2016

Kabul tarihi: 1 Mart 2016 
seçilen antibiyotik istenilen dozlarda eklenebilir. Farmakolojik olarak, her antibiyotiğin çimentoya eklenmesi uygun değildir (Tablo 1). Cerrahi sırasında hazırlanan spacer'lar, mekanik olarak daha zayıf ve kırılmaya yatkındır. Yüzeyler birbirine daha uyumsuz olup, sıklıkla harekete daha az izin verir. Dizde ve kalçada kullanılan hazır spacer ile cerrahin kendi yaptığı eklemli olan arasında, fonksiyonel sonuçlar ve enfeksiyonun eradikasyonu bakımından fark gösterilememiştir. ${ }^{[3]}$

Tablo 1. Spacer içinde kullanılabilecek mevcut olan antibiyotik ve anti-fungaller ${ }^{[3]}$

\begin{tabular}{|c|c|c|c|}
\hline Antibiyotik Grubu & Antibiyotik Tipi & Etkin olduğu organizmalar & 40 gr çimento (gr) \\
\hline Aminoglikosit & Tobramisin & $\begin{array}{l}\text { Gram-negatif bakteriler } \\
\text { (örn; Pseudomonas) }\end{array}$ & $1-4,8$ \\
\hline Aminoglikosit & Gentamisin & $\begin{array}{l}\text { Gram-negatif bakteriler Escherichia coli, Klebsiella ve } \\
\text { özellikle Pseudomonas aeroginosa } \\
\text { Ayrıca aerobik bakteriler } \\
\text { (zorunlu/fakültatif olmayan anaeroplar) }\end{array}$ & $0,25-4,8$ \\
\hline Sefalosporin, 1. nesil & Sefazolin & $\begin{array}{l}\text { Gram-pozitif enfeksiyonlar, } \\
\text { sınırlı Gram-negatif etkisi }\end{array}$ & $1-2$ \\
\hline Sefalosporin, 2. nesil & Sefuroksim & $\begin{array}{l}\text { Azalmış Gram-pozitif etkisi, } \\
\text { artmış Gram-negatif etkisi }\end{array}$ & $1,5-2$ \\
\hline Sefalosporin, 3. nesil & Seftazidim & $\begin{array}{l}\text { Gram-negatif bakteriler, } \\
\text { özellikle Pseudomonas }\end{array}$ & 2 \\
\hline Sefalosporin, 4. nesil & Sefotaksim & $\begin{array}{l}\text { Gram-negative bakteriler, } \\
\text { Pseudomonas'a karşı etkinlik yok }\end{array}$ & 2 \\
\hline Sefalosporin, 5. nesil & Seftaroiln & $\begin{array}{l}\text { Gram-negatif bakteriler, } \\
\text { Pseudomonas'a karşı etkinli yok }\end{array}$ & $2-4$ \\
\hline Fluoroquinolon & Siprofloksasin & $\begin{array}{l}\text { Gram-negatif organizmalar } \\
\text { Enterobacteriaciae'ları da içine alan etkinlik }\end{array}$ & $0,2-3$ \\
\hline Glycopeptit & Vankomsin & $\begin{array}{l}\text { Gram-pozitif bakteriler, } \\
\text { metisislin-dirençli organizmalar dahil }\end{array}$ & $0,5-4$ \\
\hline Linkosamid & Klindamisin & $\begin{array}{l}\text { Gram-pozitif koklar, } \\
\text { anaeroblar }\end{array}$ & $1-2$ \\
\hline Makrolid & Eritromisin & Aerobik Gram-pozitif koklar ve basiller & $0,5-1$ \\
\hline Polimiksin & Kolistin & Gram-negatif & 0,24 \\
\hline$\beta$-laktam & $\begin{array}{l}\text { Piperasilin-mevcut değil } \\
\text { Piptazobaktam }\end{array}$ & $\begin{array}{l}\text { Gram-negatif bakteriler (özellikle Pseudomonas), } \\
\text { Enterobakteriler ve anaeroplar }\end{array}$ & $4-8$ \\
\hline$\beta$-laktam & Aztreonam & Sadece Gram-negatif bakteriler & 4 \\
\hline$\beta$-laktamaz inhibitör & Tazobaktam & $\begin{array}{l}\text { Gram-negatif bakteriler (özellikle Pseudomonas), } \\
\text { enterobakteriler ve anaeroplar } \\
\text { Piperacillin ile kombine }\end{array}$ & 0,5 \\
\hline Oksazolidinonlar & Linezolid & $\begin{array}{l}\text { Çoklu ilaç dirençli Gram-pozitif koklar } \\
\text { (örn; MRSA) }\end{array}$ & 1,2 \\
\hline Karbapenem & Meropenem & $\begin{array}{l}\text { Gram-pozitif ve Gram-negatif bakteriler, } \\
\text { anaeroplar, } \\
\text { Pseudomonas }\end{array}$ & $0,5-4$ \\
\hline Lipopeptid & Daptomisin & Sadece Gram-pozitif organizmalar & 2 \\
\hline Antifungaller & Amfoterisin & Çoğu mantarlar & 200 \\
\hline Antifungal & Vorikanazol & Çoğu mantarlar & $300-600 \mathrm{mg}$ \\
\hline
\end{tabular}


Son zamanlarda, cerrahi sırasında hazırlanan spacer'ların mekanik ve tasarım özelliklerinin daha iyi olması için, metal veya tek kullanımlık kalıplar gündeme gelmiştir. Elle karıştırılan çimento kalıbın içerisine enjekte edilerek, yüzeyleri birbirine uyan, diz için veya anatomiye daha uygun spacer'lar elde edilmektedir. Üstelik bunlar, antibiyotik içeriği açısından da cerrahın tercihine açıtır. Tek kullanımlık spacer kalıpları, maliyetleri ve bulunabilirlikleri açısından dezavantajlıdır.

Bazı olgularda, oluşan kemik kaybı da düşünüldügünde, hazır spacer'lar stabil olarak yerleştirilemez. Bu durumlarda, hazır spacer'lar elle karıştırılan çimento ile desteklenebilir. Böylece, hem farklı antibiyotik eklemek hem de daha stabil bir spacer elde etmek mümkün olabilir (Şekil 1).

\section{ANTiBiYOTIK SEÇіMi}

Çimento içerisine konulacak antibiyotiğin tipi ve dozu, organizmanın profiline ve antibiyograma göre seçilmelidir. Polimetilmetakrilat (PMMA) çimentosunun ekzotermik bir reaksiyonla katılaşması nedeniyle, bazı antibiyotikler deaktive olur ve bu nedenle de spacer'larda her antibiyotik kullanılamaz. Seçilen antibiyotiğin bakterisit olması, çimentoyla daha iyi entegre ${ }^{[4]}$ olması için toz halinde olması, yüksek ısıda kimyasal/ farmakolojik olarak kararlı olması ve suda çözülebilmesine dikkat edilmelidir. Uygulama kolaylığı açısından, enfeksiyonların çoğunun vankomisin (40 gr'lık her çimento paketi için 1-4 gr) ve gentamisin veya tobramisin (40 gr'lık her çimento paketi için 2,4-4,8 gr) spacer ile tedavi edilebileceği akılda bulundurulmalıdır.

Ayrıca, antibiyotik seçiminde hastanın böbrek fonksiyonları ve alerji varlığı göz önünde bulundurulmalıdır. Her ne kadar bazı çalışmalar PMMA çimentosuna yüksek dozda antibiyotik eklenebildiğini ileri sürse de, antibiyotik emdirilmiş çimento spacer'ların kullanımında renal toksisite gelişebildiği bildirilmiştir. ${ }^{[5]}$

\section{SPACER'LARI HAZIRLAMA TEKNIĞi}

Antibiyotik salınmasının farmakokinetiği, çimentonun gözenekliliği (porozite), çimentonun tipi, PMMA'ya eklenen antibiyotiklerin çeşidi, spacer'ın yüzey alanı ve şekli gibi çok sayıda faktörden etkilenmektedir.

Genel ilkenin aksine, spacer hazırlanırken, vakumsuz bir kapta ve elle karıştırma tavsiye edilir; çünkü, bu yöntemle oluşan kabarcıklar poroziteyi arttırır ve antibiyotiğin salınımını kolaylaştırı. ${ }^{[6]}$ Her ne kadar spacer'lar için birincil kaygı antibiyotiğin elüzyonu olsa da, yüksek miktarda antibiyotiğin eklenmesinin, çimentonun dayanıklıığını azaltıp, kırılma riskini arttıracağı göz önünde bulundurulmalıdır. Genel olarak 4,5

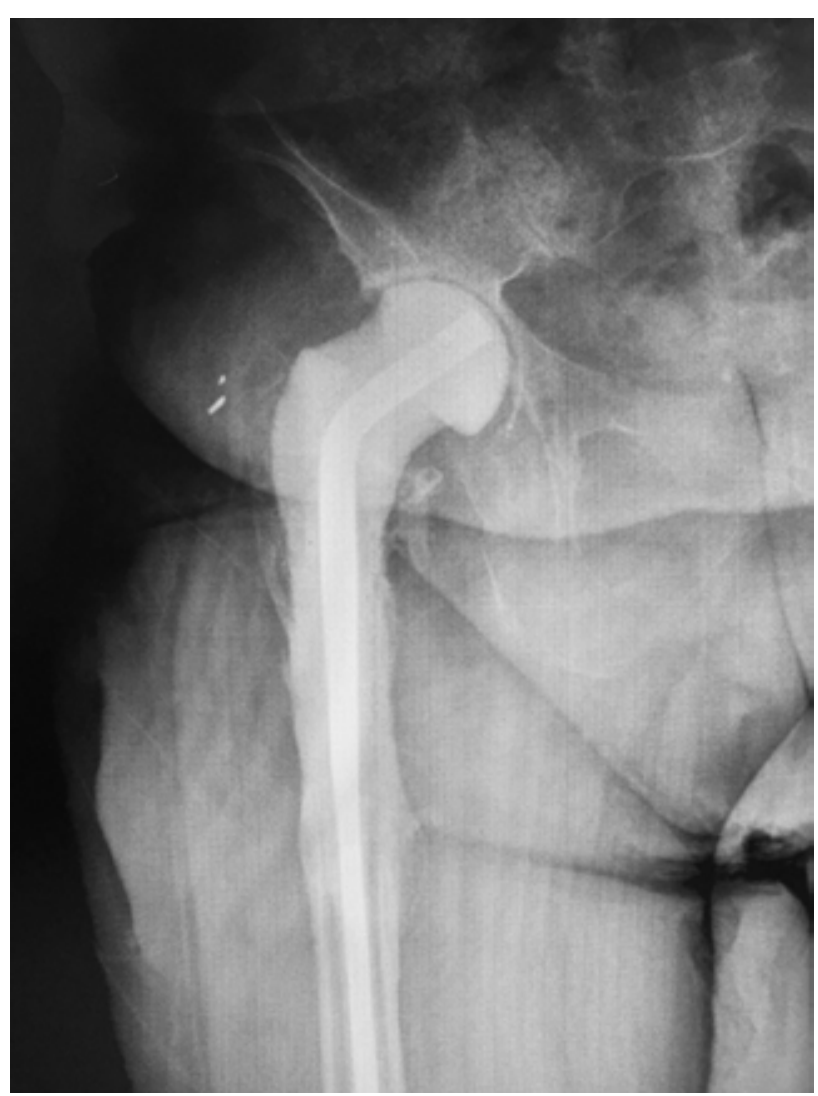

Şekil 1. Proksimal femurdaki kemik defektinin hazır spacer'ın etrafına sarılan ilave çimento ile desteklendiği görülmektedir.

gr'dan fazla toz eklenmesi, çimentoyu belirgin olarak zayıflatmaktadır. ${ }^{[7]}$

Günümüzde, uygulanan çimentoların farklı kimyasal özellikte olanları vardır. Bunlar arasından, metil metakrilat ve metil akrilat (MA-MMA) kopolimer içeren yüksek vizkozite çimentolar, diğer akrilik kemik çimentosu formülasyonlarına göre daha iyi antibiyotik salınım profiline sahiptir. ${ }^{[8]}$ Ayrıca, spacer'ın yüzeyi ne kadar genişse, antibiyotik salınımı o derecede yüksek olmaktadır.

Spacer hazırlanırken temel ilkelerden biri; lokal antibiyotik konsantrasyonunun, minimal inhibitör konsantrasyonundan ve enfekte organizmanın minimal bakteri konsantrasyonundan belirgin olarak fazla olmasını sağlamaktır. ${ }^{[9]}$ Çimentodaki antibiyotiklerin salınımının cerrahiden sonraki ilk 24-72 saatte en yüksekte olduğu gösterilmiştir. ${ }^{[10]}$ Başlangıçta çimentoda görülen yüksek salınım, spacer yüzeyinin mekanik erozyonuna bağlı gibi görünmektedir. Haftalar süren daha uzun dönemdeki salınım ise, antibiyotik yüklü kemiğin kendisi ile ilişkilidir. ${ }^{[11]}$ En iyi etki için, antibiyotiğin çimento içerisinde homojen olarak dağıtılması tavsiye edilmektedir. 


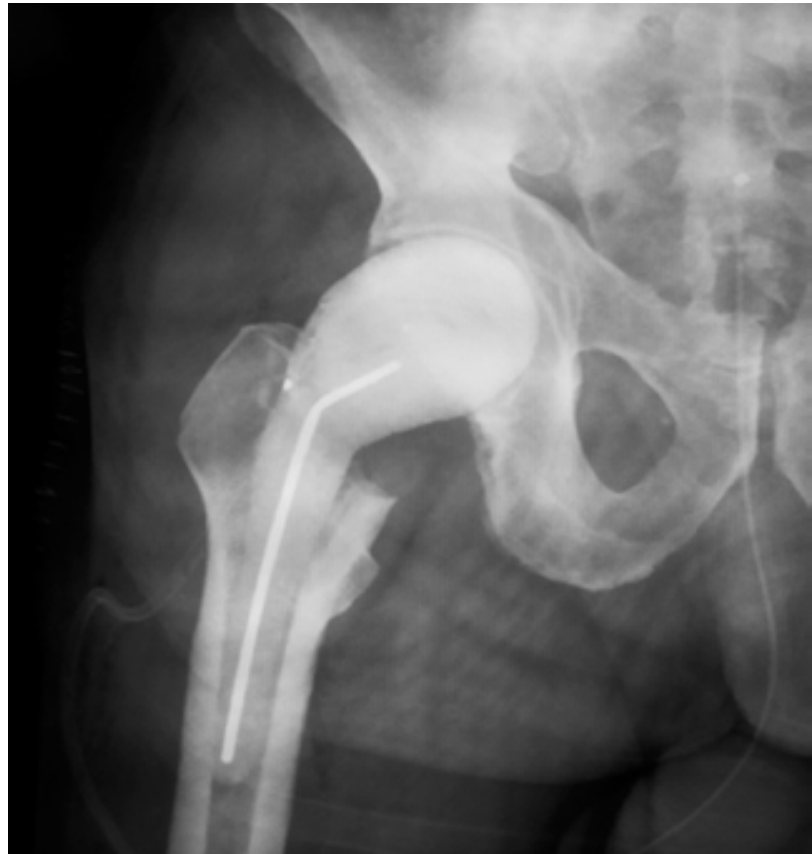

Şekil 2. Spacer uygulamasında çimentonun içerisine Kirschner teli yerleştirilmiş.

Spacer'dan antibiyotik salınımının etkisi üzerinde bir diğer faktör, kullanılan antibiyotik kombinasyonudur. Birden fazla antibiyotik eklendiğinde, her bir antibiyotiğin salınımı diğerini etkiler; çünkü, bir antibiyotik çözüldüğünde gözeneklilik artmakta ve yüzeyi değiştirmektedir ki bu da diğer antibiyotiklerin salınımını arttırmaktadır. Örneğin; karışımdaki tobramisinin dozu 2,4 gr'dan en az 3,6 gr'a yükseltildiğinde, vankomisinin elüsyonunda istatistiki olarak anlamlı bir yükselme olduğu gösterilmiştir. ${ }^{[12]}$

Hazır spacer'larda mekanik dayanıklılığı arttırmak için, içlerine metal bir destek konulduğu gibi, elle hazırlanan spacer'lara da Kirschner teli ile bir iskelet yerleştirmek önerilmektedir. Özellikle kalçada bu daha önemlidir, çünkü femur medullasına yerleştirilen kısım zaman içerisinde veya ikinci aşamadaki cerrahi sırasında kırılabilir ve cerrahi daha komplike hale gelebilir (Şekil 2).

\section{EKLEMLI VE EKLEMSIZ SPACER'LAR}

Diz ve kalçanın PEE'sinde, iki aşamalı revizyona giden olgularda, eklemli ve eklemli olmayan spacer kullanma seçenekleri mevcuttur. Günlük pratikte, eklem etrafında yumuşak doku açısından riskli bulunan hastalarda, yumuşak dokunun daha rahat iyileşmesini sağlamak amacıyla, eklemli olmayan spacer'lar tercih edilmektedir.
Önemli derecede kemik kaybı olan, yumuşak doku bütünlüğü olmayan ve yumuşak dokuların sağladığı stabiliteden yoksun hastalarda, eklemli olmayan spacer kullanımı tercih edilmelidir. Bu durumlar haricinde, kalça ve diz için eklemli veya eklemli olmayan spacer'ların kullanımı için belirgin bir kontrendikasyon yoktur.

Spacer'ları hasta fonksiyonu açısından değerlendiren az sayıda çalışmada, eklemli spacer'ın daha iyi sonuçlar ortaya koyduğu gösterilmiştir. ${ }^{[13-16]}$ Ancak, enfeksiyonu kontrol etme bakımından fark bildirilmemiştir. ${ }^{[17-19]}$ Kalçada, eklemli spacer'larda daha yüksek komplikasyon oranları bildirilmiştir. ${ }^{[20]}$

\section{KAYNAKLAR}

1. Freeman MG, Fehring TK, Odum SM, Fehring K, Griffin $\mathrm{WL}$, Mason JB. Functional advantage of articulating versus static spacers in 2-stage revision for total knee arthroplasty infection. J Arthroplasty 2007;22(8):1116-21.

2. Kim YH, Choi Y, Kim JS. Treatment based on the type of infected TKA improves infection control. Clin Orthop Relat Res 2011;469(4):977-84. Crossref

3. Citak M, Argenson JN, Masri B, Kendoff D, Springer B, Alt V, Baldini A, Cui Q, Deirmengian GK, Del Sel H, Harrer MF, Israelite CL, Jahoda D, Jutte PC, Levicoff E, Meani E, Motta F, Pena OR, Ranawat AS, Safir O, Squire MW, Taunton MJ, Vogely CH, Wellman SS. Spacers. J Arthroplasty 2014;29(2 Suppl):93-9. Crossref

4. Frommelt L. Properties of bone cement: antibiotic loaded cement. In: Frommelt L, Kuhn KD. The Well-Cemented Total Hip Arthroplasty, Part II. Berlin: Springer; 2006. p.86-92.

5. James A, Larson T. Acute renal failure after high-dose antibiotic bone cement: case report and review of the literature. Ren Fail 2015;37(6):1061-6. Crossref

6. Meyer J, Piller G, Spiegel CA, Hetzel S, Squire M. Vacuummixing significantly changes antibiotic elution characteristics of commercially available antibiotic-impregnated bone cements. J Bone Joint Surg Am 2011;93(22):2049-56. Crossref

7. Dunne NJ, Hill J, McAfee P, Kirkpatrick R, Patrick S, Tunney $M$. Incorporation of large amounts of gentamicin sulphate into acrylic bone cement: effect on handling and mechanical properties, antibiotic release, and biofilm formation. Proc Inst Mech Eng H 2008;222(3):355-65.

8. Haddad FS, Masri BA, Campbell D, McGraw RW, Beauchamp CP, Duncan CP. The PROSTALAC functional spacer in twostage revision for infected knee replacements. Prosthesis of antibiotic-loaded acrylic cement. J Bone Joint Surg $\mathrm{Br}$ 2000;82(6):807-12.

9. Kühn KD. Antibiotic loaded bone cements -antibiotic release and influence on mechanical properties. In: Walenkamp G, editor. Local Antibiotics in Arthroplasty. Stuttgart/New York: Georg Thieme Verlag; 2007.

10. Masri BA, Duncan CP, Beauchamp CP. The modified two staged exchange arthroplasty in the treatment of infected total knee replacement: The Prostalac system and other articulated spacers. In: Engh GA, Rorabeck $\mathrm{CH}$, editors. Revision Total Knee Arthroplasty, Vol 13. Baltimore, Md, USA: Williams \& Wilkins; 1997. p.394-424. 
11. Bertazzoni Minelli E, Benini A, Magnan B, Bartolozzi P. Release of gentamicin and vancomycin from temporary human hip spacers in two-stage revision of infected arthroplasty. J Antimicrob Chemother 2004;53(2):329-34.

12. Masri BA, Duncan CP, Beauchamp CP. Long-term elution of antibiotics from bone-cement: an in vivo study using the prosthesis of antibiotic-loaded acrylic cement (PROSTALAC) system. J Arthroplasty 1998;13(3):331-8.

13. Hofmann AA, Goldberg TD, Tanner AM, Cook TM. Tenyear experience using an articulating antibiotic cement hip spacer for the treatment of chronically infected total hip. J Arthroplasty 2005;20(7):874-9.

14. Fleck EE, Spangehl MJ, Rapuri VR, Beauchamp CP. An articulating antibiotic spacer controls infection and improves pain and function in a degenerative septic hip. Clin Orthop Relat Res 2011;469(11):3055-64. Crossref

15. Wei W, Kou BL, Ju RS, Lü HS. The second stage revision for infected total hip arthroplasty using antibioticloaded cement prosthesis. Zhonghua Wai Ke Za Zhi 2007;45:246-8.
16. Borowski M, Kusz D, Wojciechowski P, Cielinski Ł. Treatment for periprosthetic infection with two-stage revision arthroplasty with a gentamicin loaded spacer. The clinical outcomes. Ortop Traumatol Rehabil 2012;14(1):41-54.

17. Thabe $H$, Schill S. Two-stage reimplantation with an application spacer and combined with delivery of antibiotics in the management of prosthetic joint infection. Oper Orthop Traumatol 2007;19(1):78-100.

18. Tigani D, Trisolino G, Fosco M, Ben Ayad R, Costigliola P. Two-stage reimplantation for periprosthetic knee infection: influence of host health status and infecting microorganism. Knee 2013;20:9-18. Crossref

19. D'Angelo F, Negri L, Binda T, Zatti G, Cherubino P. The use of a preformed spacer in two-stage revision of infected hip arthroplasties. Musculoskelet Surg 2011;95(2):115-20. Crossref

20. Fink B, Grossmann A, Fuerst M, Schäfer P, Frommelt L. Twostage cementless revision of infected hip endoprostheses. Clin Orthop Relat Res 2009;467(7):1848-58. Crossref 